\title{
Reflets
}

Revue ontaroise d'intervention sociale et communautaire

\section{En Ontario, on a ce qu'il faut!}

\section{Linda Prémont}

Volume 1, numéro 1, printemps 1995

Des pratiques à notre image : défis et ressources

URI : https://id.erudit.org/iderudit/026065ar

DOI : https://doi.org/10.7202/026065ar

Aller au sommaire du numéro

Éditeur(s)

Reflets : Revue ontaroise d'intervention sociale et communautaire

ISSN

1203-4576 (imprimé)

1712-8498 (numérique)

Découvrir la revue

Citer cet article

Prémont, L. (1995). En Ontario, on a ce qu'il faut! Reflets, 1(1), 213-215.

https://doi.org/10.7202/026065ar

Tous droits réservés (C) Reflets : Revue ontaroise d'intervention sociale et communautaire, 1995

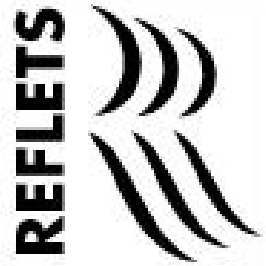

Ce document est protégé par la loi sur le droit d'auteur. L'utilisation des services d'Érudit (y compris la reproduction) est assujettie à sa politique d'utilisation que vous pouvez consulter en ligne.

https://apropos.erudit.org/fr/usagers/politique-dutilisation/ 


\title{
En Ontario, on a ce qu'il faut!
}

\author{
Linda Prémont \\ Travailleuse sociale \\ Centre de santé et services communautaires de Hamilton
}

Qu'est-ce que ça prend pour pouvoir offrir des services en français en Ontario?... Tout d'abord, des francophones. On en a! On en est! Selon le recensement de Statistique Canada de 1991, la ville de Hamilton compte environ 8515 personnes francophones.

Le Centre de santé et services communautaires de HamiltonWentworth ouvrait ses portes à l'été 1992 dans le but, très avoué, d'offrir aux francophones de cette région des services de qualité dans leur langue. L'initiative s'est avérée très justifiée puisque, jusqu'à présent, plus de 1000 personnes ont utilisé les services du Centre. Alors que certaines de ces personnes participent à des sessions de counseling individuel, de couple ou familial, d'autres font partie de divers groupes de soutien, pour les femmes ou pour les parents d'adolescents, par exemple, et d'autres encore prennent part à des soirées de discussions thématiques. Le Centre offre également un programme de prévention des agressions dans les écoles de la région.

Néanmoins, il n'est pas nécessairement toujours facile pour les intervenantes et intervenants du Centre de rejoindre la population francophone. La situation s'explique en grande partie par le fait que plusieurs personnes franco-ontariennes, n'ayant pas l'habitude d'avoir accès à des services en français, n'ont pas le réflexe de s'y diriger. La tâche de rejoindre ces personnes s'avère donc difficile et exige un grand acharnement. C'est d'ailleurs en assurant une présence constante et durable dans la communauté, en s'impliquant en tant qu'intervenante ou intervenant et en 
Reflets

facilitant la participation des personnes de la communauté aux activités du Centre que nous parvenons à rejoindre la population francophone.

L'expérience suivante illustre bien le genre de participation communautaire caractéristique du centre. Après l'obtention d'une subvention de la Direction générale de la condition féminine de l'Ontario pour développer un projet de prévention de l'agression sexuelle pour les femmes, le centre invite un comité composé de femmes de la communauté à s'occuper entièrement de la planification de la soirée. L'atelier a été présenté en français par cinq conférencières, chacune abordant un thème spécifique de l'agression sexuelle, notamment, les conséquences aux niveaux social, légal et de la santé, l'expérience particulière des femmes de minorités ethniques et la prévention. Un buffet ainsi qu'un service de garde ont été offerts aux 23 participantes et ont été grandement appréciés.

Voici ce que nous avons retenu de cette expérience. La participation des femmes de la communauté au sein du comité organisateur a facilité l'expression de leurs besoins et ceux des femmes qu'elles connaissaient. Ainsi, nous, intervenantes et intervenants, n'avons pas eu à tenter de deviner la nature de ces besoins ou d'offrir un atelier n'y répondant pas adéquatement. De plus, l'expérience a démontré l'importance des services de soutien (buffet, garde d'enfants) pour faciliter la participation des femmes qui connaissent des difficultés d'ordre économique et pratique. Finalement, la présentation de plusieurs volets reliés à un même thème a permis la transmission d'informations variées, aptes à répondre aux besoins d'un plus grand nombre de personnes.

La plus grande leçon que nous pouvons tirer de cette expérience est que la communauté francophone a la capacité de se prendre en charge, de s'organiser. Lorsque les intervenants croient tout offrir «sur un plateau d'argent», ils risquent souvent de passer à côté des vrais besoins des gens. Nous devons reconnaître, d'ailleurs, que nous avons souvent cette tendance à organiser la vie des personnes sans les consulter suffisamment. Lorsque des programmes ou des ateliers s'organisent sans l'apport de consultation communautaire, il ne faut pas s'étonner du peu de succès 
de certaines de nos initiatives. Car, entre nous, qui est le mieux placer pour identifier ses besoins?

Oui, en Ontario, on a ce qu'il faut. On a des intervenantes et des intervenants qui croient aux francophones et qui soutiennent leur cause. Mais surtout, on a des gens à consulter, des gens qui connaissent leurs besoins. Ils sont là. Parfois, ils chuchotent, ils murmurent. À nous de tendre l'oreille. Il ne faudrait pas les oublier car les services, les programmes, les ateliers... ce sont elles et eux... Heureusement!!! 